\title{
The use of Geomorphological modelling in landscape design and planning
}

\begin{abstract}
The discipline of civil engineering has a rich history in the development of models that interpret Geomorphological processes, both in physical as well as digital formats. This article explores the potential of these types of simulations in order to become a creative engine in the landscape design and planning processes. In order to do that, it introduces a description of the types of models being discusses altogether with the forms of knowledge being generated. It describes the methods of work used by designers and argues of the potential intersection with civil engineering discipline. It then introduces a number of cases studies of the utilisation of these models in the creative industry, both in academic environment as well as art installations. It uses the examples to conclude with a reflection on how to use this knowledge further when collaborating with landscape design related disciplines.
\end{abstract}

Keywords: landscape design, geomorphology, simulation, modelling, tacit knowledge, intuition
Volume 3 Issue 5 - 2017

\section{Eduardo Rico Carranza}

Architectural Association School of Architecture, UK

Correspondence: Eduardo Rico Carranza,Architectural Association School of Architecture, London, UK, Email erico@relationalurbanism.com

Received: September 01, 2017 | Published: December 08, 2017

\section{Geomorphological modelling in civil engineering}

The applied nature of civil engineering has historically shaped the approach of its professionals towards the development of Geomorphological models and simulations. The aim of these models is the understanding of natural processes and more typically development of predictions how these natural processes will act and interact with human structures, existing or proposed. It is this projective attitude of the civil engineer that makes our work relevant to other disciplines dealing with design at territorial levels and that rely on our knowledge in order to substantiate their proposals. In this sense, landscape architects and urban planners need to work in close collaboration with engineers in order to successfully deliver large scale projects that interact with large territorial features such as rivers, dune systems, deltas or similar scale formations. What this article argues is that in order to develop a healthier and more productive relationship between landscape architects and civil engineers, it is worth analysing the type of knowledge produced by Geomorphological models and compare it with the type of knowledge that designers need to manage in their creative process. Only doing so, we may be able to emphasize aspects of our collaboration and nurture new forms of professional practice. The tradition of geomorphological modelling in civil engineering dates to back the studies carried out in natural sciences, namely geology, which began using a number of physical models in order to understand natural phenomena and explain the patterns of distribution of materials in the earth surface as the result of internal tectonic forces acting over millions of years. These first models (also called analogous models) date as far back as 1812, when the geologist James Hall used layers of clay in order to replicate in small scale the types of structures that he found in nature such as folds and faults. James Hall carried out this work in combination with other experiments that were trying to ascertain how rocks and minerals would behave differently when molten and how they would recuperate its solid nature when cooled. The idea behind the model is that clay layers subject to confined stress in a (see Figure 1 of similar experiment by H.M. Cadell using wet sand and plaster $)^{1}$ will exhibit a deformation pattern which is structurally similar to that one of igneous materials subject to high pressure and temperatures. The behaviour of clay, wet sand or plaster in terms of its fluency at small scale (both geometrical as well as temporal) and the one of rock at large scale are analogous (hence their name). What is interesting for the purposes of this article is the intuitive jump made by James Hall \& HM Cadell ${ }^{1}$ when finding such a connection between so seemingly different materials. For all its rigour and scientific excellence, their methods were underpinned by a great deal of imagination and pragmatism that initially led Hall to believe that we could learn things about nature (and up to a certain point predict certain behaviour) when observing the behaviour of materials at a small scale (Figure 1).

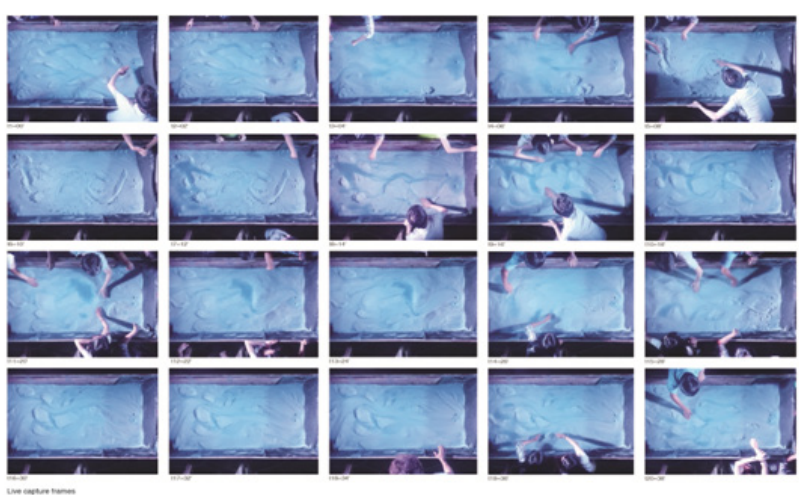

Figure I Photo do H.M.Cadell's "squeeze box" as part of his mountain building experiment.

Similar development of physical models were carried out in the fields of hydraulics and aerodynamics and it was thanks to the development of Dimensional Analysis during the beginning of the 19th century that the results from measured in these models (fluid 
velocity, pressure or others) could be translated across scales. This could be done providing that certain relationships between variables (speed, viscosity, density or others) are maintained within acceptable limits. This brought an important advancement of the use of models which went that they could move from being descriptive to become more predictive tools geared for precise interventions and management strategies. Examples of these models carried out at the territorial scale go as large as the heroic Mississippi Basin model carried out by the US Army Corps of Engineers (Figure 2). The advent of digital models applied to geomorphology brought a new level of precision and accuracy as the computing power became more available and the simulations themselves are more comprehensive and sophisticated. Physical models have partially lost protagonism due to their higher coast and the inherent difficulty in scaling down material properties. However they remain nevertheless key in highly complex situations or as forms of calibrating digital models which are later scaled up or used in more general terms. This relationship between digital and physical points to an important aspect of the type of knowledge generated by both types of models: While digital models help engineers run cheaper and faster models for many more situations, physical models help ascertain complex local behaviours in ways that digital models cannot. The physical counterpart may allow us to "see" what is happening in real time and help us discover things such as local effects that may have bearings in the overall pattern that we want to simulate. The "directness" of the physical model helps bring an intuitive level of understanding of process, which can be later turned into mathematical expression if it. It is precisely the use of intuition that is required in the generation of physical models and their digital translations what makes civil engineering a particularly relevant practice for designers. Far from limiting itself to be a source of analytic results, the discipline of environmental modelling can leverage in this intuitive character of knowledge and make further links to other discipline, where it plays a much more central role, as we shall see in the following section.

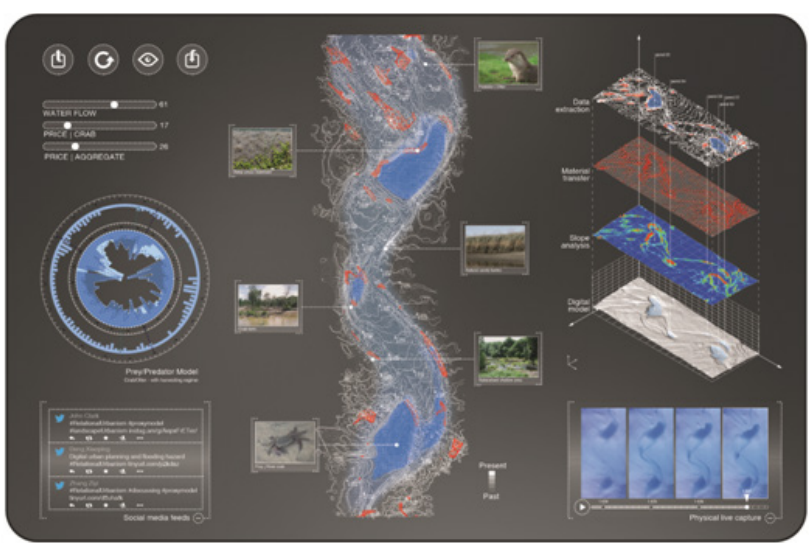

Figure 2 Photo of the Mississippi river model built in Clinton, Mississippi by the US Army Corps of Engineers.

\section{Design and the tacit dimension of knowledge}

Landscape architecture and planning are disciplines that work with forms of knowledge that share analytical components with civil engineers but also need other forms of knowledge related to creative industry. The term "tacit knowledge" was coined by the sociologist Michael Polanyi ${ }^{2}$ in the 60 's to denote a form of knowledge that cannot be expressed or codified in an explicit manner but that exists and can have practical consequences nonetheless. Using Polanyi's famous sentence, "we know more than we can tell". Tacit forms of knowledge are present in our everyday life and range from the ability to ride a bicycle to the skill of a pianist, all of which must be learnt by "doing"; in other words, one cannot learn to ride a bicycle by reading about it, but must first observe the master and interiorize his skills by means of practicing. From a professional perspective, tacit knowledge has been claimed to be at the root of the work of creative industries. Artists, designers, architects and other professionals rely on forms of knowledge and skills do not necessarily travel through normal channels, but that is acquired through direct interaction. This can take place of day to day contact and interaction with the workspace or direct physical contact in case of machinery, artisanship or similar. Tacit knowledge is also linked to more close or intimate relationship between the human and the subject matter of study. Bringing the example of the sculptor, Polanyi describes how the act of using the tool requires interiorizing its dimensions and treating it almost as an extension of the body. Similar accounts of interiorized knowledge are also given by the philosopher Henry Bergson, ${ }^{3}$ who describes intuition as a form of approaching or sympathising with things from "within" them. What is interesting about tacit knowledge is that Polanyi began to formulate its existence in his book "Personal Knowledge" as a critique to common perception of scientific knowledge. ${ }^{4}$ For Polanyi, the scientific method has more of an intuitive dimension and sympathetic connection with the subject matter than it is generally acknowledged. Many discoveries and advancements begin with intuitions of how nature works which are later substantiated and corroborated with scientific rigour. Understanding the tacit dimension of science, he argues, will unlock its full potential and contribution to society. Coming back to the use of models in geomorphology, it is difficult to disagree with Polanyi when thinking about degree of intuition behind the work of Civil Engineers. The scale and material leaps done by Hall and Cadell in the devising of analogue models or the work of the scientist observing a physical model in search for unexpected effects, these are all examples to the great deal of tacit form of thinking required in our profession in a daily basis. The challenge is to look for forms of collaboration such that engineers (with relatively stronger analytical component) interact effectively with other designers (with relatively stronger tacit component). Being aware of each professional's strengths is the first step towards the fabrication of these bridges, particularly in the case of large sale territorial projects, with the complexity that these entail. What follows is a number of academic examples of architect student work making use of physical simulations or river and ecological systems where the nature of the simulation was central to the design concept. ${ }^{5}$

\section{Academic experiments with geodynamic models}

The work included in this section has been carried out by students of Eduardo Rico in the Architectural Association as well as collaboration with Enriqueta Llabres in the context of the Bartlett School of Architecture during the period 2013-2014. It points towards the direction of linking the use of geomorphological models to the generation of landscape design concepts in novel and innovative ways along the lines previously introduced. In the first case shown (Figures $3 \& 4$ ) the students were trying to understand how flooding occurred in the agricultural areas around the Arga River, Spain. For this purpose the group analysed a time base evolution of a flood event using a cellular automata based flood and sediment model, using the results to locate areas where water breached the exiting defences. The idea behind the project was to provide flood storage within the agricultural fields and do so in a way that was managed in terms of flood 
protection downstream, but that would generate landscapes buffers and ecologically protected areas with certain aesthetic and ecological value. The simulation, in this case, proved to be an invaluable tool that revealed the hierarchy of spaces that were more or less susceptible to flooding, this helping landscape architects develop evidence based forms of design (Figure 5).

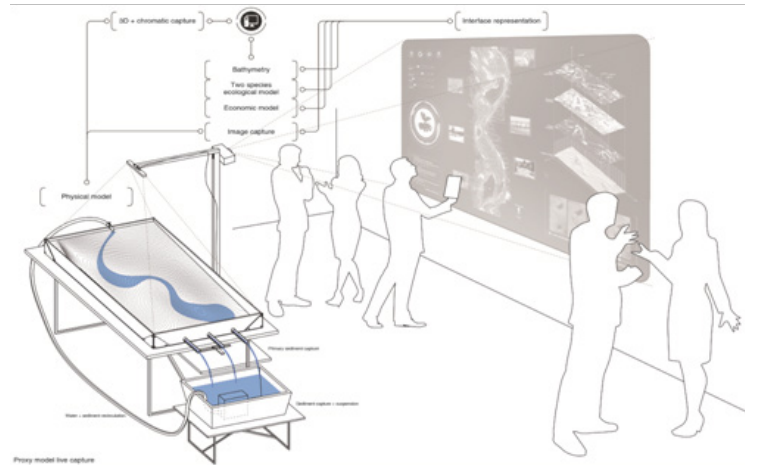

Figure 3 Image showing study of flood impact of different options (above) and $3 \mathrm{~d}$ representation of results of preferred options (below).

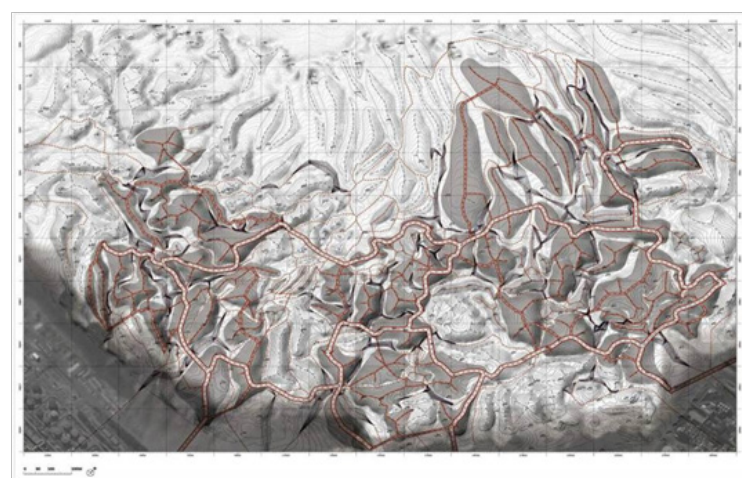

Figure 4 Setup and results from physical model of gilbert delta.

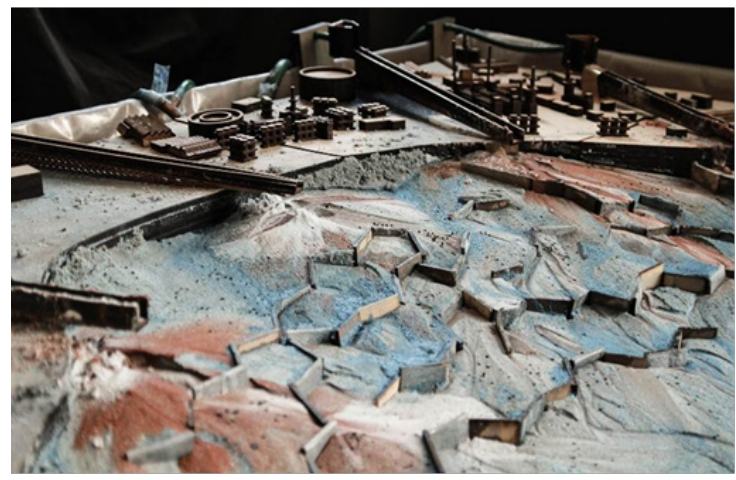

Figure 5 Use of delta model for development of landscape proposals (ibid).

In the second case, the students used a basic model of generation of a gilbert delta by dropping sand and water in a semi flooded tank (Figure 6). This was used initially as a way of teaching the students the development of these types of deltas and then as a purely qualitative design tool of how to control water and sediment movement in the generation of new landscapes. The academic project was set in the tar sands mining region of Alberta, where the process of final treatment of sand tailings in large scale ponds generate morphologies not dissimilar to those obtained in the analogue model. In this case the water was lightly tinted in blue, which helped to digitally scan the model searching for colour coding and further turning it into a digital 3D environment. During the design process the students could interact with the flow of sediments and water (Figure 7), learning how to divert it, generate accumulations and different morphologies though the positioning of rigid structures in the flow. Further work of cataloguing shapes and interventions followed with final attempts to generate an alternative form of tailing pond where the tailings would generate a terraced landscape park once the process is over (Figure $8 \& 9)$. What was interesting from this case was how the live character of the simulations helped the designers understand the minutiae of sedimentary formations and allowed them to interact with the material. While the simulation had more of a qualitative nature than the previous example (ie, it is hard trying to extract hard data from it) it provided a much more direct tool to develop interventions and generate ideas for formal proposals. A third example, also developed by Eduardo Rico and Enriqueta Llabres, was implemented as an art installation in the Future City Workshop, Wuhan. In this case a live river model was generated with a $2 \mathrm{~m} \times 1 \mathrm{~m}$ sand box which was digitally captured and where ecological systems were mathematically modelled over a hypothetical riparian system formed in the digital model (Figure 8). The idea behind the installation was to allow people interact with the river using their own hands so that they could experience in a matter of minutes how the morphology would change (typically forming braided channels) and how ecologies would react. The installation was meant to make explicit how human interaction and natural processes interact in this case in a compressed environment, both in term of scale as well as time. In this third example, the qualitative nature of the tool, while not suitable as a projective tool useable for a proposal, nevertheless enabled a playful character that helped transmit a message about environmental management and the need to understand the effects of our interventions in nature.
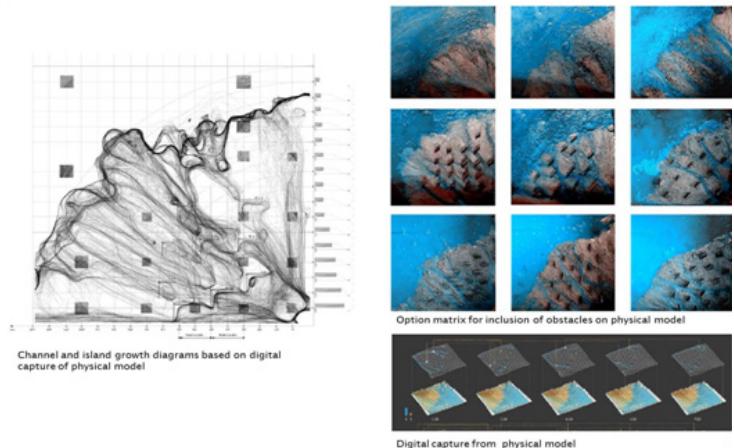

Figure 6 Master plan proposal extracted from physical model (ibid).

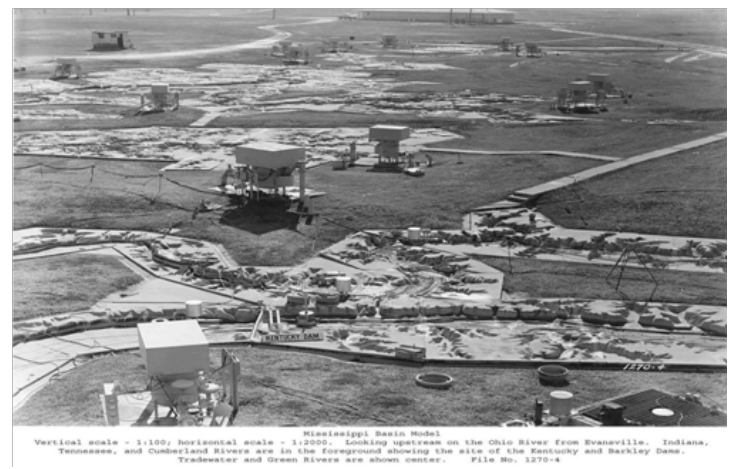

Figure 7 Installation setup with river model, digital capture and data projection. 


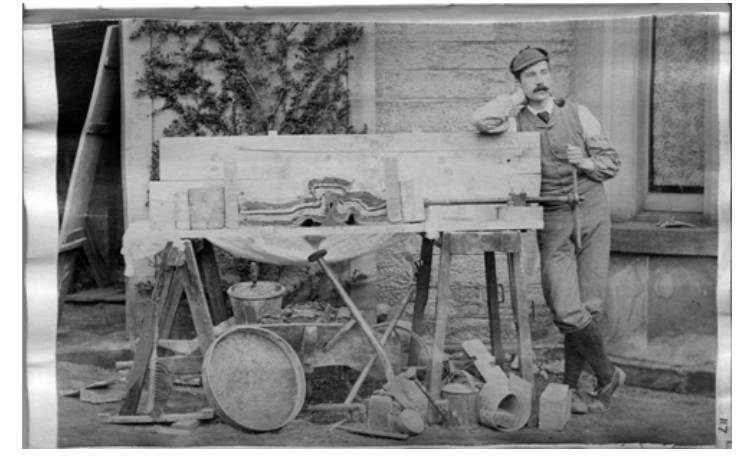

Figure 8 People interacting with model (ibid).

\section{Conclusion}

\section{Interacting with design teams}

As we have seen in the previous cases, the work with geomorphological simulations has both a quantitative and qualitative nature. What is important is to understand how much of those components are required at each stage of design, with territorial data perhaps requiring higher degree of precision (first case of river) but in the design of concepts or prototypes being more loose or qualitative (second case of the mines). There is a substantial benefit in understanding the intuitive nature of the knowledge associated with geomorphological modelling. Trying to link it to other forms of knowledge and bring it to multidisciplinary teams in novel and unexpected ways may open up room for collaborations and further access to valuable markets and clients.

\section{Acknowledgments}

None.

\section{Conflicts of interest}

None.

\section{References}

1. Angela NH Creager, Elizabeth Lunbeck, M Norton Wise. Naomi Oreskes: From Scaling to Simulation. Changing Meanings and Ambitions of Models in Geology. USA: in Science without Laws: Model Systems, Cases, Exemplary Narratives, Edited by Duke University Press; 2009;93124.

2. M Polanyi. The tacit dimension, Doubleday \& Company, inc. USA: New York; 1966. p. 3-25.

3. H Bergson. The Creative Mind: An Introduction to Metaphysics. USA: Philosophical Library; 1946.

4. M Polanyi. Personal Knowledge: Towards a post-critical philosophy. USA: Routledge \& Kegan Paul ltd; 1958.

5. Tom Coulthard. The Cellular Automaton Evolutionary Slope and River Model (CAESAR). Australia: University of Hull; 2006 